\title{
Age, gender, and current living status were associated with perceived access to treatment among Canadians using a cross sectional survey
}

\author{
Catherine W. T. Chan ${ }^{1}$, Amédé Gogovor ${ }^{2,3,4,5}$, Marie-France Valois ${ }^{1,2}$ and Sara Ahmed ${ }^{1,3,4,5^{*}}$
}

\begin{abstract}
Background: Access, particularly timely access, to care is the Canadian public's most important healthcare concern. The drivers of perceived appropriateness of access to care among patients with at least one chronic health condition (CHC) are not, however, well defined. This study evaluated whether personal characteristics, self-reported health status and care received were associated with patients' perception of effective access in managing a chronic illness.

Methods: The study population ( $n=619)$ was drawn from a representative sample of the adult Canadian population who reported having $\geq 1$ CHC in the 2013-2014 Health Care in Canada survey. Ordinal regression, with the continuation ratio model, was used to evaluate association of perceived level of access to treatment with socio-demographic factors, perceived health status and care utilization experience.

Results: Factors most closely associated with patients' satisfaction with care access were: age, sex, current cohabitation, care affordability, and availability of support and information to help manage their CHCs. Individuals, particularly females, $<35$ years, currently living alone, with poor access to professional support or information and who feel affordability of care has worsened over the past five years were more likely to report a poorer level of treatment access.

Conclusions: Individuals living alone, who are younger, and women may be especially susceptible to lower perceived access to care of $\mathrm{CHCs}$ and a sense of pessimism about things not getting better. Further evaluation of the reasons behind these findings may help develop effective strategies to assist these populations to access the care they need.
\end{abstract}

Keywords: Chronic health conditions, Access to treatment, Health Care in Canada Survey

\section{Background}

For many Canadians, the universal, publicly-funded healthcare system plays an essential, if less than perfect, role in defining the nation's identity [1]. All provincial and territorial health care insurance plans ensure patients have access to medically necessary services without having to pay at the point of care. The definition of medically necessary, however, can

\footnotetext{
* Correspondence: sara.ahmed@mcgill.ca

'Department of Epidemiology, Biostatistics and Occupational Health, McGill University, 1020 Pine Avenue West, Montreal, QC H3A 1A2, Canada ${ }^{3}$ Centre for Outcomes Research and Evaluation, McGill University Health Centre, 5252 Boul. De Maisonneuve, Montreal, QC H4A 3S5, Canada Full list of author information is available at the end of the article
}

vary by jurisdiction [2, 3]. A study conducted by the Organization for Economic Co-operation and Development (OECD) noted marked variation in hospital admissions, and surgical and diagnostic procedures both within and between provinces and territories, beyond or below levels explained by patient need, which suggest the delivery of services without evidence of increased benefit to patients or the subsistence of unmet healthcare needs, respectively [3]. In the case that needs are unmet, it would be even more critical among those with chronic health conditions (CHCs). Responsible for 38 million deaths in 2012 (68\% of all deaths), CHCs are a leading cause of

(c) The Author(s). 2018 Open Access This article is distributed under the terms of the Creative Commons Attribution 4.0 International License (http://creativecommons.org/licenses/by/4.0/), which permits unrestricted use, distribution, and reproduction in any medium, provided you give appropriate credit to the original author(s) and the source, provide a link to the Creative Commons license, and indicate if changes were made. The Creative Commons Public Domain Dedication waiver (http://creativecommons.org/publicdomain/zero/1.0/) applies to the data made available in this article, unless otherwise stated. 
death worldwide; and this statistic is projected to increase to 52 million by $2030[4,5]$. It is a particularly grim statistic for patients with limited access to healthcare services needed to manage chronic conditions.

Although healthcare in Canada is universal, expenditures per capita are unevenly distributed among $\mathrm{Ca}-$ nadians [6]. Approximately two-thirds of healthcare costs are spent on treating adults with multiple $\mathrm{CHCs}$ as these individuals tend to utilize healthcare services more often $[4,6]$. Multiple $\mathrm{CHCs}$ also tend to manifest in individuals as they age [4]. More effective treatments for cancer, diabetes, chronic respiratory diseases, and other $\mathrm{CHCs}$ has contributed to greater life expectancy among patients and a steady rise in the prevalence of individuals with multiple chronic diseases [6]. As patients with greater demands on healthcare expenditures and resources continue to grow, the risk of unmet healthcare needs will steadily increase and the effective management of these cases will become extremely important.

It has been estimated that 1 in 7 adults with a chronic health condition $(\mathrm{CHC})$ have unmet care needs, including inadequate access to care $[7,8]$. Access is a complex, multidimensional concept that is central to charting the performance of healthcare systems [9]. Recent data from the 2013-2014 Health Care in Canada (HCIC) survey indicate, in fact, that lack of timely access is the most important care issue among the public [10]. An understanding of the population experiencing unmet healthcare needs will help to target healthcare services to the most vulnerable groups. In previous studies looking at the Canadian population, healthcare utilization (i.e., the number of consultations with a healthcare professional in the previous year), self-reported health status, the number of $\mathrm{CHCs}$, the type of $\mathrm{CHCs}$, age, sex, race, education, and income of the patient were shown to be associated with how well a patient perceives their healthcare needs to be met $[8,11]$. These studies also reported that, compared to patients without a chronic condition, those with $\mathrm{CHCs}$ were more likely to report an unmet healthcare need [8, 11]; Ronksley et al. (2012) showed that the likelihood of this also increased with the number of $\mathrm{CHCs}$ [8]. Although the drivers of suboptimal access remain incompletely defined among patients with chronic conditions, public perception of access is practically important; it is negatively associated with rates of hospitalization for CHCs [12].

The objective of this study was to evaluate whether patient demography, perceived health status, number and severity of $\mathrm{CHCs}$ and care utilization experiences might drive perceptions of timeliness and effectiveness of care access among patients with CHCs. Using data from the 2013-2014 HCIC survey [10], we evaluated the relationship between such sociodemographic and health status/care variables and $\mathrm{CHC}$ patients' perceived access to effective care.

\section{Methods}

\section{Study population}

The dataset consisted of responses from the online HCIC survey conducted by Pollara Inc. in 2013-2014, and, included representative samples of the Canadian adult public, health professionals (nurses, pharmacists, physicians) and administrators [13]. For the study analysis, only the public survey was utilized.

Canadians throughout all provinces were recruited, selecting those 18 years of age or older. An e-mail was sent to a random sample of eligible individuals. Those who accepted the e-mail invitation to participate in this study were provided with the survey. Through this process, the participants who responded to the survey were required to self-select into the sample at two stages: i.e., at the initial sign-up and then again by accepting the e-mail invitation if received.

No quotas were enforced during the sampling process. As such, weights were used for each set of responses accounted for age and sex distributions within province corresponding to the demographics in the 2011 Census to correct for the sampling method.

\section{Study variables \\ Primary outcome of interest}

The outcome of interest was perceived access to treatment for the management of their $\mathrm{CHC}(\mathrm{s})$. In the survey, the participants were asked, "Do you have access to the treatments you need to manage your condition(s)?" Respondents were allowed to choose one of five possible responses: always, often, sometimes, rarely, or never. Due to the distribution of the responses in the dataset, cross-tabulations and regression analyses were performed grouping the latter three response options (i.e. sometimes, rarely, and never) into one category, while the respondents who answered "always" or "often" remained separate categories.

\section{Independent variables}

The Behavioural Model of Health Services Use described by Andersen [14] was used as a guide to determine the variables that would be of interest in the regression model. This model provides a framework to evaluate the factors that impact the use of health services and healthcare access [14]. Considering the factors raised in this framework, we incorporated variables that may be potential determinants of perceived access to treatment (refer to Tables 1 and 2, and Appendix 1 and Table A4.1 from Additional file 1). 


\section{Statistical analysis}

As our outcome of interest is ordinal and consists of three separate categories, the data was analyzed using an ordinal regression with the continuation ratio model to determine the association between the perceived access to treatment of the respondents and our predictors of interest [15]. Prior to univariate analyses, spearman correlations were performed in order to check if any independent variables were highly correlated with one another to ensure there would not be collinearity. If one or more variables were shown to be correlated (i.e., $\rho \geq$ 0.5 ), only one such variable was added into subsequent analysis.

Two separate ORs were produced for each model: $\mathrm{OR}_{1}$ compared the odds of the individuals in a specific category who feel they often/sometimes/rarely/never have access to treatment to the odds of those who always have access; $\mathrm{OR}_{2}$ compared the odds of those who feel they sometimes/rarely/never have access to those who often have access.

A multivariate ordinal regression analysis was performed to determine which factors might be potential drivers of suboptimal access to treatment. All statistical analysis was conducted using R 3.0.1 and SAS 9.3. Sensitivity analysis was conducted to ensure the robustness of the results.

\section{Results}

\section{Descriptive statistics}

Of the 1000 respondents, 619 individuals reported having at least one $\mathrm{CHC}$. Among those who provided a response, $247(40 \%)$ responded that they "always" had access to the treatment(s) required to manage their CHC, 170 (27\%) responded that they "often" had access, while 202 (33\%) claimed that they "sometimes/rarely/ never" have access to treatment(s). Of the 619 respondents, the top three diagnoses reported were heart disease, stroke or high blood pressure (42\%); arthritis (40\%); and other unspecified health conditions (33\%). More information regarding the diagnoses seen among the respondents can be found in Table A2.1 in Additional file 1 . The distribution of sociodemographic characteristics and health-related measures among the respondents can be seen in Table 1. The list and frequency of the patient-reported reasons for poor access are shown in Table A5.1 in Additional file 1.

\section{Regression analysis}

\section{Personal characteristics}

According to our fully adjusted model, age, gender, and current cohabitation with another individual were significantly associated with self-reported access to treatment among those with at least one CHC (Table 2). Individuals over the age of 35 were less likely to report often, sometimes, rarely, or never having access to treatment compared to always having access to treatment. Furthermore, compared to those $<35$ years, seniors (aged 65+) were $87 \%$ less likely to report their access to treatment as anything less than "Always" $\left(\mathrm{OR}_{1}=0.13\right.$, 95\% CI: 0.04-0.41). Females were twice as likely to report a level of access below "Often" compared to males $\left(\mathrm{OR}_{2}=2.09,95 \% \mathrm{CI}: 1.15-3.77\right)$. Also, those currently living alone were 2.40 times (95\% CI: 1.04-5.53) more likely to report poorer access (i.e., less than "Always" having access) than those living with another individual. Other personal characteristics did not have a statistically significant association with perceived access to treatment.

\section{Chronic disease diagnosis}

The number and the type of CHCs (diabetes, heart disease/stroke/ hyper-tension, or cancer) were not statistically associated with the perceived accessibility to treatment.

\section{Perceived affordability}

Compared to individuals who did not perceive affordability of the health system or its services as having worsened over the past five years, respondents who felt that affordability had worsened moderately were 2.17 times (95\% CI: 1.03-4.58) more likely to report often/ sometimes/rarely/never (vs. always) having access to treatment. None of the remaining associations were statistically significant.

\section{Type of care received}

Receiving support from health professionals and the information needed to manage $\mathrm{CHCs}$ were factors that were strongly associated with an individual's perceived accessibility. Individuals who reported sometimes, rarely, or never receiving support from their HCPs were 5.01 times (95\% CI: 2.37-10.60) more likely to report often to never (vs. always) receiving access to treatment and 3.75 times (95\% CI: 1.31-10.72) more likely to report sometimes to never (vs. often) having access. Those who reported only often receiving support were also 3.35 times (95\% CI: 1.81-6.19) more likely to perceive treatment access at a level below "always." Similarly, individuals who felt that the information to manage their $\mathrm{CHCs}$ was sometimes, rarely, or never available were 19.27 times (95\% CI: 8.35-44.45) more likely to report often to never (vs. always) having access to treatment, and 4.40 times (95\% CI: 1.78-10.85) more likely to perceive treatment as sometimes to never (vs. often) accessible. Although not statistically significant, those without a doctor or HCP to help manage their condition were less likely to always or often feel that treatment was accessible. 
Table 1 Characteristics of $\mathrm{HClC}$ respondents from the public according to the perceived level of access to treatment(s) needed to manage chronic health condition(s) $(\mathrm{CHC})(n=619)$

\begin{tabular}{|c|c|c|c|c|c|c|}
\hline \multirow[t]{4}{*}{ Characteristic } & \multirow{4}{*}{$\begin{array}{l}\text { Total n } \\
\text { (\%) }\end{array}$} & \multicolumn{5}{|c|}{ Has access to treatment(s) needed to manage $\mathrm{CHC}(\mathrm{s})$ : } \\
\hline & & Always & Often & Sometimes & Rarely & Never \\
\hline & & n (\%) & $n(\%)$ & $\mathrm{n}(\%)$ & n (\%) & $n(\%)$ \\
\hline & & $n=247(40)$ & $n=170(27)$ & $n=131(21)$ & $n=53(9)$ & $n=18(3)$ \\
\hline \multicolumn{7}{|l|}{ Sex } \\
\hline Female & $320(52)$ & $116(36)$ & $83(26)$ & $84(26)$ & $29(9)$ & 8 (3) \\
\hline \multicolumn{7}{|l|}{ Age } \\
\hline$<35$ years & $70(11)$ & $10(14)$ & $27(39)$ & $26(37)$ & $6(9)$ & $1(1)$ \\
\hline $35-44$ years & $80(13)$ & $32(40)$ & $22(28)$ & $13(16)$ & $9(11)$ & $4(5)$ \\
\hline $45-54$ years & $137(22)$ & $42(31)$ & $38(28)$ & $38(28)$ & $15(11)$ & 4 (3) \\
\hline $55-64$ years & $162(26)$ & $61(38)$ & $47(29)$ & $33(20)$ & $16(10)$ & 5 (3) \\
\hline$\geq 65$ years & $170(27)$ & $102(60)$ & $36(21)$ & $21(12)$ & $7(4)$ & $4(2)$ \\
\hline \multicolumn{7}{|l|}{ Number of $\mathrm{CHCs}$} \\
\hline 1 & $261(42)$ & $111(43)$ & $65(25)$ & $54(21)$ & $18(7)$ & $13(5)$ \\
\hline 2 & $172(28)$ & $71(41)$ & $49(28)$ & $34(20)$ & $16(9)$ & $2(1)$ \\
\hline$\geq 3$ & $186(30)$ & $65(35)$ & $56(30)$ & $43(23)$ & $19(10)$ & $3(2)$ \\
\hline \multicolumn{7}{|l|}{ Household Income } \\
\hline$<\$ 50,000$ & $175(28)$ & $55(31)$ & $42(24)$ & $43(25)$ & $26(15)$ & $9(5)$ \\
\hline$\$ 50,000-\$ 74,999$ & $235(38)$ & $104(44)$ & $61(26)$ & $53(23)$ & $13(6)$ & $4(2)$ \\
\hline$\$ 75,000-\$ 99,999$ & $75(12)$ & $33(44)$ & $25(33)$ & $12(16)$ & $4(5)$ & $1(1)$ \\
\hline$\geq \$ 100,000$ & $64(10)$ & $26(41)$ & $21(33)$ & $10(16)$ & $5(8)$ & $2(3)$ \\
\hline Prefer not to say & $70(11)$ & $29(41)$ & $21(30)$ & $13(19)$ & $5(7)$ & 2 (3) \\
\hline \multicolumn{7}{|l|}{ Region $^{a}$} \\
\hline Ontario & $237(38)$ & $106(45)$ & $66(28)$ & $46(19)$ & $11(5)$ & $8(3)$ \\
\hline Quebec & $123(20)$ & $44(36)$ & $37(30)$ & $27(22)$ & $12(10)$ & $3(2)$ \\
\hline British Columbia & $79(13)$ & $34(43)$ & $16(20)$ & $17(22)$ & $10(13)$ & $2(3)$ \\
\hline Alberta & $61(10)$ & $20(33)$ & $20(33)$ & $17(28)$ & $4(7)$ & $0(0)$ \\
\hline Atlantic & $80(13)$ & $32(40)$ & $20(25)$ & $15(19)$ & $9(11)$ & $4(5)$ \\
\hline Prairies & $39(6)$ & $11(28)$ & $11(28)$ & $9(23)$ & $7(18)$ & 1 (3) \\
\hline \multicolumn{7}{|l|}{ Health Insurance Plan } \\
\hline Yes & $312(50)$ & $136(44)$ & $90(29)$ & $61(20)$ & $21(7)$ & $4(1)$ \\
\hline No & $307(50)$ & $111(36)$ & $80(26)$ & $70(23)$ & $32(10)$ & $14(5)$ \\
\hline \multicolumn{7}{|l|}{ Marital Status } \\
\hline Single, never married & $115(19)$ & $34(30)$ & $38(33)$ & $26(23)$ & $15(13)$ & $2(2)$ \\
\hline Married/Common-law & $364(59)$ & $154(42)$ & $95(26)$ & $80(22)$ & $25(7)$ & $10(3)$ \\
\hline Divorced/separated & $95(15)$ & $38(40)$ & $22(23)$ & $21(22)$ & $12(13)$ & $2(2)$ \\
\hline Widowed & $41(7)$ & $20(49)$ & $13(32)$ & $3(7)$ & $1(2)$ & $4(10)$ \\
\hline Prefer not to say & $4(1)$ & $1(25)$ & $2(50)$ & $1(25)$ & $0(0)$ & $0(0)$ \\
\hline \multicolumn{7}{|l|}{ Residence } \\
\hline Urban & $509(82)$ & $202(40)$ & $136(27)$ & $115(23)$ & $44(9)$ & $12(2)$ \\
\hline Rural & $110(18)$ & $45(41)$ & $34(31)$ & $16(15)$ & $9(8)$ & $6(5)$ \\
\hline \multicolumn{7}{|c|}{ Currently live with another person } \\
\hline Yes & $445(72)$ & $189(42)$ & $118(27)$ & $94(21)$ & $33(7)$ & $11(2)$ \\
\hline No & $174(28)$ & $58(33)$ & $52(30)$ & $37(21)$ & $20(11)$ & $7(4)$ \\
\hline \multicolumn{7}{|l|}{ Self-rated Health } \\
\hline Excellent/Nery Good & $186(30)$ & $96(52)$ & $48(26)$ & $28(15)$ & $8(4)$ & $6(3)$ \\
\hline Good & $246(40)$ & $102(41)$ & $71(29)$ & $47(19)$ & $20(8)$ & $6(2)$ \\
\hline Fair/Poor & $187(30)$ & 49 (26) & $51(27)$ & $56(30)$ & 25 (13) & $6(3)$ \\
\hline
\end{tabular}

${ }^{a}$ Territories were excluded since no individuals were sampled from this region 
Table 2 Adjusted odds ratios and associated 95\% confidence intervals for the perceived likelihood of often/sometimes/rarely/never vs. always and sometimes/rarely/never vs. often receiving the access to treatment needed to manage $\mathrm{CHCs}$

\begin{tabular}{|c|c|c|c|c|c|c|}
\hline \multirow[t]{2}{*}{ Variable of Interest } & \multicolumn{2}{|l|}{$\mathrm{OR}_{1}{ }^{\mathrm{a}}$} & \multicolumn{2}{|c|}{$\mathrm{OR}_{2}^{\mathrm{b}}$} & \multicolumn{2}{|c|}{ OR $R_{\text {cumulative }}$} \\
\hline & $\overline{\mathrm{OR}}$ & $95 \% \mathrm{Cl}$ & $\overline{\mathrm{OR}}$ & $95 \% \mathrm{Cl}$ & $\overline{\mathrm{OR}}$ & $95 \% \mathrm{Cl}$ \\
\hline \multicolumn{7}{|l|}{ Age } \\
\hline$<35$ years & 1 & & 1 & & 1 & \\
\hline $35-44$ years & 0.21 & $0.07,0.66^{*}$ & 0.89 & $0.31,2.54$ & 0.48 & $0.24,0.97^{*}$ \\
\hline $45-54$ years & 0.30 & $0.10,0.91^{*}$ & 1.24 & $0.49,3.18$ & 0.65 & $0.34,1.26$ \\
\hline $55-64$ years & 0.31 & $0.10,0.96^{*}$ & 1.84 & $0.69,4.94$ & 0.81 & $0.41,1.61$ \\
\hline$\geq 65$ years & 0.13 & $0.04,0.41^{*}$ & 1.24 & $0.40,3.80$ & 0.38 & $0.18,0.78^{*}$ \\
\hline \multicolumn{7}{|l|}{ Sex } \\
\hline Male & 1 & & 1 & & 1 & \\
\hline Female & 1.28 & $0.76,2.17$ & 2.09 & $1.15,3.77^{*}$ & 1.50 & $1.04,2.16^{*}$ \\
\hline \multicolumn{7}{|l|}{ Household income } \\
\hline$<\$ 50,000$ & 1 & & 1 & & 1 & \\
\hline$\$ 50,000$ to $\$ 74,999$ & 0.75 & $0.38,1.49$ & 0.71 & $0.33,1.52$ & 0.75 & $0.47,1.21$ \\
\hline$\$ 75,000$ to $\$ 99,999$ & 0.89 & $0.36,2.22$ & 0.47 & $0.17,1.31$ & 0.72 & $0.38,1.37$ \\
\hline$\geq \$ 100,000$ & 1.05 & $0.38,2.90$ & 0.37 & $0.12,1.09$ & 0.68 & $0.34,1.38$ \\
\hline Prefer not to say & 1.27 & $0.51,3.18$ & 0.56 & $0.21,1.51$ & 0.92 & $0.49,1.73$ \\
\hline \multicolumn{7}{|l|}{ Marital status } \\
\hline Single & 1 & & 1 & & 1 & \\
\hline Common-law/Married & 0.92 & $0.38,2.23$ & 1.37 & $0.52,3.60$ & 1.05 & $0.57,1.94$ \\
\hline Divorced/Separated/Wi-dowed/Prefer not to say & 0.49 & $0.21,1.14$ & 1.36 & $0.58,3.19$ & 0.74 & $0.42,1.29$ \\
\hline \multicolumn{7}{|l|}{ Residence } \\
\hline Urban & 1 & & 1 & & 1 & \\
\hline Rural & 1.07 & $0.56,2.04$ & 0.58 & $0.28,1.22$ & 0.85 & $0.53,1.35$ \\
\hline \multicolumn{7}{|l|}{ Currently live with another person } \\
\hline Yes & 1 & & 1 & & 1 & \\
\hline No & 2.40 & $1.04,5.53^{*}$ & 1.43 & $0.56,3.67$ & 1.80 & $1.00,3.25$ \\
\hline \multicolumn{7}{|l|}{ Private Insurance } \\
\hline Yes & 1 & & 1 & & 1 & \\
\hline No & 1.08 & $0.63,1.86$ & 1.08 & $0.59,1.97$ & 1.09 & $0.74,1.58$ \\
\hline \multicolumn{7}{|c|}{ Number of different types of prescription medications currently taking } \\
\hline$\leq 1$ & 1 & & 1 & & 1 & \\
\hline 2 & 1.28 & $0.50,3.28$ & 1.04 & $0.36,3.02$ & 1.09 & $0.57,2.12$ \\
\hline 3 & 1.34 & $0.50,3.58$ & 1.20 & $0.38,3.76$ & 1.20 & $0.60,2.41$ \\
\hline$\geq 4$ & 1.48 & $0.61,3.59$ & 0.52 & $0.19,1.41$ & 1.02 & $0.55,1.91$ \\
\hline \multicolumn{7}{|l|}{ Self-rated Health } \\
\hline Good & 1 & & 1 & & 1 & \\
\hline Excellent & 0.85 & $0.21,3.50$ & 0.34 & $0.06,1.91$ & 0.69 & $0.24,1.99$ \\
\hline Very Good & 0.89 & $0.48,1.66$ & 1.12 & $0.54,2.33$ & 1.03 & $0.66,1.61$ \\
\hline Fair & 1.07 & $0.55,2.07$ & 1.76 & $0.84,3.70$ & 1.45 & $0.91,2.31$ \\
\hline Poor & 1.31 & $0.41,4.17$ & 1.33 & $0.48,3.74$ & 1.17 & $0.57,2.40$ \\
\hline \multicolumn{7}{|l|}{ Number of $\mathrm{CHCs}^{\mathrm{C}}$} \\
\hline 1 & 1 & & 1 & & 1 & \\
\hline 2 & 1.52 & $0.79,2.91$ & 1.27 & $0.61,2.63$ & 1.33 & $0.84,2.10$ \\
\hline$\geq 3$ & 2.03 & $0.90,4.57$ & 1.30 & $0.53,3.20$ & 1.50 & $0.86,2.60$ \\
\hline
\end{tabular}

Type of Chronic Health Condition (CHC) 
Table 2 Adjusted odds ratios and associated 95\% confidence intervals for the perceived likelihood of often/sometimes/rarely/never vs. always and sometimes/rarely/never vs. often receiving the access to treatment needed to manage CHCs (Continued)

\begin{tabular}{|c|c|c|c|c|c|c|}
\hline \multirow[t]{2}{*}{ Variable of Interest } & \multicolumn{2}{|l|}{$\mathrm{OR}_{1}{ }^{\mathrm{a}}$} & \multicolumn{2}{|l|}{$\mathrm{OR}_{2}^{\mathrm{b}}$} & \multicolumn{2}{|c|}{$\mathrm{OR}_{\text {cumulative }}$} \\
\hline & $\overline{O R}$ & $95 \% \mathrm{Cl}$ & $\overline{O R}$ & $95 \% \mathrm{Cl}$ & $\overline{O R}$ & $95 \% \mathrm{Cl}$ \\
\hline \multicolumn{7}{|l|}{ Diagnosed with Diabetes } \\
\hline No & 1 & & 1 & & 1 & \\
\hline Yes & 0.79 & $0.41,1.53$ & 0.60 & $0.26,1.36$ & 0.76 & $0.47,1.22$ \\
\hline \multicolumn{7}{|l|}{ Diagnosed with Heart Disease, Stroke, or High Blood Pressure } \\
\hline No & 1 & & 1 & & 1 & \\
\hline Yes & 0.76 & $0.41,1.38$ & 0.91 & $0.46,1.80$ & 0.85 & $0.56,1.29$ \\
\hline \multicolumn{7}{|l|}{ Diagnosed with Cancer } \\
\hline No & 1 & & 1 & & 1 & \\
\hline Yes & 0.73 & $0.32,1.68$ & 0.67 & $0.25,1.79$ & 0.70 & $0.39,1.26$ \\
\hline \multicolumn{7}{|l|}{ Perceived Affordability } \\
\hline \multicolumn{7}{|l|}{ Summary of perceived affordability } \\
\hline Did not perceive affordability as having worsened & 1 & & 1 & & 1 & \\
\hline Worsened somewhat & 0.98 & $0.47,2.04$ & 1.07 & $0.43,2.65$ & 1.02 & $0.59,1.75$ \\
\hline Worsened moderately & 2.17 & $1.03,4.58^{*}$ & 1.93 & $0.79,4.68$ & 1.92 & $1.13,3.25^{*}$ \\
\hline Worsened a lot & 2.35 & $0.99,5.56$ & 2.22 & $0.84,5.85$ & 2.25 & $1.22,4.15^{*}$ \\
\hline Worsened completely & 1.92 & $0.83,4.39$ & 1.52 & $0.62,3.74$ & 1.82 & $1.02,3.26^{*}$ \\
\hline \multicolumn{7}{|l|}{ Type of Care Received } \\
\hline \multicolumn{7}{|l|}{ Work with doctor or team of HCPs to manage $\mathrm{CHC}(\mathrm{s})$} \\
\hline Doctor & 1 & & 1 & & 1 & \\
\hline Team & 1.21 & $0.62,2.37$ & 0.58 & $0.26,1.29$ & 0.89 & $0.55,1.44$ \\
\hline Neither & 1.85 & $0.73,4.74$ & 1.36 & $0.57,3.24$ & 1.82 & $0.99,3.37$ \\
\hline \multicolumn{7}{|l|}{ Receive the support needed from HCPs to manage $\mathrm{CHC}(\mathrm{s})$} \\
\hline Always & 1 & & 1 & & 1 & \\
\hline Often & 3.35 & $1.81,6.19^{*}$ & 1.43 & $0.53,3.82$ & 2.86 & $1.75,4.68^{*}$ \\
\hline Sometimes/Rarely/Never & 5.01 & $2.37,10.60^{*}$ & 3.75 & $1.31,10.72^{*}$ & 5.47 & $3.09,9.70^{*}$ \\
\hline \multicolumn{7}{|l|}{ Have access to the information needed to manage $\mathrm{CHC}(\mathrm{s})$} \\
\hline Always & 1 & & 1 & & 1 & \\
\hline Often & 6.43 & $3.59,11.53^{*}$ & 0.56 & $0.24,1.34$ & 3.21 & $2.02,5.10^{*}$ \\
\hline Sometimes/Rarely/Never & 19.27 & $8.35,44.45^{*}$ & 4.40 & $1.78,10.85^{*}$ & 14.71 & $8.25,26.24^{*}$ \\
\hline \multicolumn{7}{|l|}{ Emergency Room (ER) Visits } \\
\hline \multicolumn{7}{|l|}{ ER visit due to $\mathrm{CHC}(\mathrm{s})$} \\
\hline Never & 1 & & 1 & & 1 & \\
\hline$\leq 12$ months & 1.67 & $0.63,4.40$ & 2.13 & $0.74,6.16$ & 2.19 & $1.09,4.41^{*}$ \\
\hline$>12$ months & 1.31 & $0.77,2.22$ & 1.05 & $0.58,1.91$ & 1.17 & $0.81,1.70$ \\
\hline \multicolumn{7}{|l|}{ Adherence Variable } \\
\hline \multicolumn{7}{|l|}{ Adherence to medications } \\
\hline High & 1 & & 1 & & 1 & \\
\hline Medium & 1.78 & $0.97,3.26$ & 0.91 & $0.45,1.84$ & 1.36 & $0.88,2.09$ \\
\hline Low & 1.49 & $0.59,3.75$ & 1.72 & $0.69,4.29$ & 1.51 & $0.83,2.76$ \\
\hline No prescription medications taken on a regular basis/Missing & 2.00 & $0.76,5.23$ & 1.04 & $0.37,2.97$ & 1.48 & $0.75,2.90$ \\
\hline
\end{tabular}

${ }^{*}$ Significant at $p<0.05$

${ }^{\mathrm{a}} \mathrm{OR}_{1}$ represent odds ratio comparing the Often/Sometimes/Rarely/Never has access versus the Always has access

${ }^{\mathrm{b}} \mathrm{OR}_{2}$ represent odds ratio comparing the Sometimes/Rarely/Never has access versus the Often has access

${ }^{c}$ The variable with information about the number of $\mathrm{CHCs}$ was included despite showing non-significant values in a few initial models to ensure comparability between our analysis and that of a previous study [8] 


\section{Emergency department visits}

The time since the last emergency department visit for a $\mathrm{CHC}$-related issue was not a significant predictor of respondent perceptions on treatment access. The initial statistically significant effect observed in the univariate model (Table A4.1 in Additional file 1) was largely removed after adjusting for the personal characteristics of those surveyed.

\section{Adherence to medication}

The level of adherence to medications reported by the respondents initially conveyed a dose-response relationship after adjusting for the personal characteristics of the individual, where those who were less adherent were progressively more likely to report poorer access to treatment (Table A4.1 in Additional file 1). However, this factor was no longer a significant predictor of individuals' perceptions of access after adjusting for other variables.

\section{Discussion}

This study provided several insights into factors that are associated with perceived access to care. Our analysis supported that individuals with at least one $\mathrm{CHC}$ were more likely to report poorer access to treatment if they were $<35$ years, female, living alone, reported a more pessimistic view of care affordability, and self-reported less than always or often receiving adequate professional support and information to manage their conditions. In contrast to previous studies [11, 16, 17], income, residence (urban/rural), and self-rated health were not associated with self-reported access among those with CHCs. Additionally, the number and the type of $\mathrm{CHCs}$ were not significant predictors of access to care [8]. This contrast may be explained by the fact that, unlike prior studies, our sample included only individuals with $\geq 1 \mathrm{CHC}$.

A previous study using 2000/2001 Canadian Community Health Survey (CCHS) data reported that those who were female, younger, white, more highly educated, and earning a lower income were more likely to report suboptimal access to health care [11]. Although the HCIC survey did not ask for the participant's level of education and ethnicity or cultural background, our results similarly showed that younger individuals and females were more likely to report poorer access to treatment. In Canada, a higher prevalence of chronic pain and depression is consistently reported among women $[18,19,20,21]$ - a statistic reflected in our sample where a slightly higher proportion of women (52\%) reported having a $\mathrm{CHC}$, and $\sim 15 \%$ of females, as opposed to $\sim 10 \%$ of males, reported being diagnosed with a mental health condition. The impact of these seemingly non-fatal chronic health disorders are often overlooked in terms of health service use despite effective treatment strategies in primary care [20, 22, 23]. As such, it is not surprising that women tend to perceive treatment access in a poorer light.

The perceptions of how affordable treatments or healthcare services have been shown to directly impact treatment access among Canadians. Although healthcare in Canada is publicly funded, out-of-pocket expenditures still occur. Results from the 2013 Commonwealth Fund International Health Policy Survey showed that 9 to $20 \%$ of Canadians spent over $\$ 1000$ out-of-pocket on healthcare in that year [24]. In 2013, approximately 1 in 12 Canadians reported not filling prescriptions or missing a dose as a result of cost while $6 \%$ cited the cost of medical tests or treatments as the reason for not undergoing doctor-recommended procedures [24].

Our analysis showed that those currently living alone were more likely to report poor access to treatment. Using CCHS data, living arrangement was found to be significantly associated with unmet health care needs among young adults (aged 18-30 years), with those living alone being more likely to report unmet needs compared to those living with others, parents, or parents and spouse [25]. Another study reported that elderly individuals living only with their spouses were significantly more likely to receive preventive care (e.g. routine physical check-ups) [26]. Thus, living with another individual appears to increase healthcare encounters, which may in turn impact public perceptions of access to care.

In our model, it was observed that support from HCPs and the provision of information required to manage $\mathrm{CHCs}$ were associated with respondent perceptions of treatment access. Although the low frequencies for certain response categories may have resulted in less precise estimates of association, previous work has suggested that useful health information has the potential to facilitate a patient's awareness of their disease, and they are better equipped to choose their care plan and carry it out [27]. Past studies have shown that patients with a deeper understanding of their illness and with support from others are able to better cope with their $\mathrm{CHC}$ through more effective use of available resources and engagement in behaviours that may influence the nature of their patient experience $[27,28]$. Studies have also reported that individuals with chronic illness were more likely to use health information and self-care resources (e.g. self-care books, telemedicine services, or the Internet) $[29,30]$. However, despite the various avenues for information available, and the empowering effect that this information provides, a 2005 survey found that patients still view physicians as the most trusted source for health information $[27,31]$. As such, it is not surprising 
that our analysis showed an association between the availability of support from $\mathrm{HCPs}$ and respondent perceptions of treatment accessibility.

\section{Limitations}

Gaps in chronic disease care has been reported between races in terms of the level of access and the availability of a usual source of medical care, while the level of education attained has also been shown to be associated with the likelihood of having access to treatments and care-seeking behaviours [11, 32, 33]. Due to limitations in our data, we were unable to adjust for these factors. We were also unable to adjust for whether or not the respondent received specialty care to assess its impact on access to care, particularly among those with more $\mathrm{CHCs}$. As such, residual confounding may remain and should be investigated in future studies. Furthermore, the online administration of the HCIC could have hindered the participation of respondents with visual or physical impairments - patients who may not be able to respond to the questions without the aid of a caregiver. In the cases where these impairments are chronic, we may introduce selection bias into our study as data collection for respondents with these $\mathrm{CHCs}$ would be impeded. Lastly, some variables had small frequencies for some response categories (e.g. access to needed information), resulting in less precise estimates of association (Refer to Table A3.1 in Additional file 1).

\section{Strengths}

Our study provided an overview of potential factors that may affect optimal access to treatment for patients with $\mathrm{CHCs}$ to manage their conditions. These results may provide a means to more effectively judge areas that healthcare programs or interventions should target to ensure improvements in chronic disease care. The online format of the survey also served as a strength since it may have encouraged more accurate reporting by respondents for sensitive information, and allowed for efficiency in survey distribution, data collection, and analysis (e.g. circumventing potential data entry errors). Although limitations in the data available through the HCIC survey precludes the making of causal inferences from the statistical analysis, our results will serve as a platform for future studies and provide insight on where resources should be allocated to ensure individuals with $\mathrm{CHCs}$ receive high quality care.

\section{Conclusions}

Access to treatment was rated more poorly among those who are $<35$ years, female, living alone, feel that the affordability of health services has worsened, and feel ill-equipped to manage their $\mathrm{CHCs}$ - making them more vulnerable to the consequences of untreated health conditions and its related comorbidities. Further evaluation of the reasons behind these findings can help develop effective strategies to help these populations access the care they need. Strategies to enable healthcare-seeking behaviours, as well as creating opportunities for social support have been shown to protect against unmet needs, and thus, have the potential to facilitate treatment access $[25,26]$. Ultimately, however, these strategies may only improve perceptions of treatment access without effecting clinical outcomes [34, 35]. As such, evidence to show whether improved perceptions of treatment access can accurately reflect access levels and positively impact clinical outcomes remains a priority.

\section{Additional file}

Additional file 1: This file provides additional data tables describing our study population and analysis. Appendix 1 provides a brief overview of how we constructed the summary variables for several multi-question concepts, including perceived affordability of the healthcare system or its services and medication adherence. Appendix 2 provides a frequency distribution of the $\mathrm{CHCs}$ reported by patients in the study population. Appendix 3 provides a frequency distribution for the additional covariates included in the ordinal regression model, outside of the sociodemographic factors seen in Table 1. These frequencies are stratified by the respondents' reported level of access to treatment(s) needed to manage their CHCs. Appendix 4 provides the results from the univariate regression analysis. Appendix 5 looks into the self-reported reasons for not always having access to treatment to manage $\mathrm{CHCs}$, cited by patients in the study population who perceive their level of access as "Often" or "Sometimes/Rarely/Never.". (DOCX 84 kb)

\section{Abbreviations}

CCHS: Canadian Community Health Survey; CHC: Chronic health condition; ER: Emergency room; HCIC: Health Care in Canada; HCP: Health care provider

\section{Acknowledgements}

The authors are grateful for the support of the Health Care in Canada Survey partners and for Terrence Montague and Joanna Nemis-White for reviewing the initial version of the manuscript.

\section{Funding}

The funding, including in-kind contribution was provided by the Health Care in Canada Survey partners:

Canadian Cancer Society.

Canadian Foundation for Healthcare Improvement.

Canadian Home Care Association.

Canadian Hospice Palliative Care Association.

Canadian Medical Association.

Canadian Nurses Association.

Constance Lethbridge Rehabilitation Centre (McGill-affiliated).

Care Net Health Management Consulting.

Health Charities Coalition of Canada.

HealthCareCAN.

Institute of Health Economics.

Institute of Work and Health.

Merck Canada.

Pollara Inc.

Strive Health Management.

Availability of data and materials

The data that support the findings of this study are available from the corresponding author on reasonable request.

Authors' contributions

The conception of the study objectives and design of the analysis and interpretation of results was completed by CC, M-FV, AG, and SA. AG and SA 
contributed to the acquisition of the data. CC and M-FV performed the data analysis. All authors made significant contributions to the writing and revision of the manuscript. All authors read and approved the final manuscript.

\section{Ethics approval and consent to participate}

Permission necessary to access and use data from the $\mathrm{HClC}$ survey conducted by Pollara Inc. was obtained prior to conducting this analysis. The data obtained from the HCIC survey was de-identified.

\section{Competing interests}

The authors declare that they have no competing interests.

\section{Publisher's Note}

Springer Nature remains neutral with regard to jurisdictional claims in published maps and institutional affiliations.

\section{Author details \\ 'Department of Epidemiology, Biostatistics and Occupational Health, McGill University, 1020 Pine Avenue West, Montreal, QC H3A 1A2, Canada. 2Department of Medicine, McGill University, 687 Pine Avenue West, Ross Building, Montreal, QC H3A 1A1, Canada. ${ }^{3}$ Centre for Outcomes Research and Evaluation, McGill University Health Centre, 5252 Boul. De Maisonneuve, Montreal, QC H4A 355, Canada. ${ }^{4}$ School of Physical and Occupational Therapy, McGill University, 3654 Prom Sir-William-Osler, Montreal, QC H3G 1Y5, Canada. ${ }^{5}$ Centre de recherche interdisciplinaire en réadaptation (CRIR), Constance Lethbridge Rehabilitation Center du CIUSSS de Centre-Ouest-de-l'̂le-de-Montréal, 7005 de Maisonneuve Boulevard West, Montreal, QC H4B 1T3, Canada.}

\section{Received: 19 August 2017 Accepted: 18 May 2018}

\section{Published online: 19 June 2018}

\section{References}

1. Soroka SN, Patrick F. The sources of attitudes on the Canadian healthcare system: a report to the Canadian Health Services Research Foundation. Ottawa: Canadian Health Services Research Foundation; 2011. p. 34

2. Government of Canada: Canada's Health Care System. https://www.canada ca/en/health-canada/services/health-care-system/reports-publications/ health-care-system/canada.html (2017). Accessed 18 Nov 2017.

3. OECD. Geographic Variations in Health Care: What Do We Know and What Can Be Done to Improve Health System Performance? In: OECD Health Policy Studies; 2014.

4. $\mathrm{ClH}$. Chronic Disease Management in Primary Health Care: A Demonstration of EMR Data for Quality and Health System Monitoring. In: Chronic Disease Management in Primary Health Care. Ottawa: Canadian Institute for Health Information; 2014. p. 1-16.

5. WHO: Global status report on noncommunicable diseases 2014. In. Geneva: World Health Organization; 2014: 298.

6. Wodchis WP, Austin PC, Henry DA. A 3-year study of high-cost users of health care. CMAJ. 2016;188(3):182-8.

7. Ronksley PE, Sanmartin C, Campbell DJ, Weaver RG, Allan GM, McBrien KA, Tonelli M, Manns BJ, Hennessy D, Hemmelgarn BR. Perceived barriers to primary care among western Canadians with chronic conditions. Health Rep. 2014:25(4):3-10

8. Ronksley PE, Sanmartin C, Quan H, Ravani P, Tonelli M, Manns B, Hemmelgarn BR. Association between chronic conditions and perceived unmet health care needs. Open Med. 2012;6(2):e48-58.

9. Levesque J-F, Harris MF, Russell G. Patient-centred access to health care: conceptualising access at the interface of health systems and populations. Int J Equity Health. 2013;12(1):18.

10. Nemis-White J, Torr E, Gogovor A, Marshall L, Ahmed S, Aylen J, Montague T. Stakeholder surveys of Canadian Healthcare performance: what are they telling us? who should be listening? who should be acting, and how? Healthcare Quarterly. 2014;17(4):22-7.

11. Kasman NM, Badley EM. Beyond access: who reports that health care is not being received when needed in a publicly-funded health care system? Can J Public Health. 2004;95(4):304-8.

12. Bindman AB, Grumbach $K$, Osmond D, Komaromy M, Vranizan K, Lurie N, Billings J, Stewart A. Preventable hospitalizations and access to health care. Jama. 1995;274(4):305-11.
13. Ahmed S, Marshall L, Gogovor A, Morton W, Norman J, Nemis-White J, Montague T, for Health Care in Canada Survey Members (2014). Challenges and opportunities: results of the 2013-2014 Health Care in Canada survey. http://www.hcic-sssc.com (2015). Accessed 17 June 2015.

14. Andersen RM. Revisiting the behavioral model and access to medical care: does it matter? J Health Soc Behav. 1995;36(1):1-10.

15. Scott SC, Goldberg MS, Mayo NE. Statistical assessment of ordinal outcomes in comparative studies. J Clin Epidemiol. 1997;50(1):45-55.

16. $\mathrm{ClHI}$. Disparities in primary health care experiences among Canadians with ambulatory sensitive conditions. In: Disparities in Primary Health Care Experiences Among Canadians With Ambulatory Care Sensitive Conditions. Ottawa: Canadian Institute for Health Information; 2012. p. 1-22.

17. Nurullah AS, Northcott HC, Harvey MD. Public assessment of key performance indicators of healthcare in a Canadian province: the effect of age and chronic health problems. Springerplus. 2014;3:28.

18. Schopflocher D, Taenzer $P$, Jovey R. The prevalence of chronic pain in Canada. Pain Res Manag. 2011;16(6):445-50.

19. Reitsma ML, Tranmer JE, Buchanan DM, Vandenkerkhof EG. The prevalence of chronic pain and pain-related interference in the Canadian population from 1994 to 2008. Chronic Dis Inj Can. 2011;31(4):157-64.

20. Boulanger A, Clark AJ, Squire P, Cui E, Horbay GLA. Chronic pain in Canada: Have we improved our management of chronic noncancer pain? Pain Res Manag. 2007;12(1):39-47.

21. Patten SB, Kennedy SH, Lam RW, O'Donovan C, Filteau MJ, Parikh SV, Ravindran AV. Canadian Network for Mood and Anxiety Treatments (CANMAT) clinical guidelines for the management of major depressive disorder in adults. I. Classification, burden and principles of management. J Affect Disord. 2009;117(Suppl 1):S5-14.

22. Malmusi D, Artazcoz L, Benach J, Borrell C. Perception or real illness? How chronic conditions contribute to gender inequalities in self-rated health. Eur J Public Health. 2012;22(6):781-6.

23. Verbrugge LM, Patrick DL. Seven chronic conditions: their impact on US adults' activity levels and use of medical services. Am J Public Health. 1995; 85(2):173-82.

24. Health Council of Canada: Where you live matters: Canadian views on health care quality. Results from the 2013 Commonwealth Fund International Health Policy Survey of the General Public. In: Canadian Health Care Matters, Bulletin 8. Toronto: Health Council of Canada; 2014.

25. Marshall EG. Do young adults have unmet healthcare needs? J Adolesc Health. 2011;49(5):490-7.

26. Lau DT, Kirby JB. The relationship between living arrangement and preventive care use among community-dwelling elderly persons. Am J Public Health. 2009;99(7):1315-21.

27. Winkelman WJ, Leonard KJ, Rossos PG. Patient-perceived usefulness of online electronic medical records: employing grounded theory in the development of information and communication technologies for use by patients living with chronic illness. J Am Med Inform Assoc. 2005;12(3): 306-14.

28. Gustafson DH, Hawkins R, Boberg E, Pingree S, Serlin RE, Graziano F, Chan $\mathrm{CL}$. Impact of a patient-centered, computer-based health information/ support system. Am J Prev Med. 1999;16(1):1-9.

29. Wagner $\mathrm{TH}$, Hibbard JH. Who uses self-care books, advice nurses, and computers for health information? Int J Technol Assess Health Care. 2001; 17(4):590-600.

30. Stellefson M, Chaney B, Barry AE, Chavarria E, Tennant B, Walsh-Childers K, Sriram PS, Zagora J. Web 2.0 chronic disease self-management for older adults: a systematic review. J Med Internet Res. 2013;15(2):e35.

31. Hesse BW, Nelson DE, Kreps GL, Croyle RT, Arora NK, Rimer BK, Viswanath K. Trust and sources of health information: the impact of the Internet and its implications for health care providers: findings from the first Health Information National Trends Survey. Arch Intern Med. 2005;165(22):2618-24.

32. Nguyen M, Ugarte C, Fuller I, Haas G, Portenoy RK. Access to care for chronic pain: racial and ethnic differences. J Pain. 2005;6(5):301-14.

33. Shi L, Chen CC, Nie X, Zhu J, Hu R. Racial and socioeconomic disparities in access to primary care among people with chronic conditions. J Am Board Fam Med. 2014;27(2):189-98.

34. King JS, Eckman MH, Moulton BW. The potential of shared decision making to reduce health disparities. J Law Med Ethics. 2011;39(Suppl 1):30-3.

35. Clark NM, Nelson BW, Valerio MA, Gong ZM, Taylor-Fishwick JC, Fletcher M. Consideration of shared decision making in nursing: a review of clinicians' perceptions and interventions. Open Nurs J. 2009;3:65-75. 